\title{
Moving patients beyond injury and back to work
}

$\mathrm{T}$

his month, JFP tackles a topic - work disability - that might, at first, seem a bit outside our usual wheelhouse of clinical review articles. (See page 264.)

Work disability is, however, a very important topic. The authors point out that "... primary care clinicians are asked to provide guidance about work activities in nearly $10 \%$ of their patient encounters; however, $25 \%$ of those clinicians thought they had little influence over work disability outcomes." This statement suggests that we need to learn more about managing work-related disability and how to influence patients' outcomes in a positive manner.

\section{I suspect that} we tend to be pessimistic about our ability to influence patient outcomes because we are uncertain about the best course of action.
I suspect that we tend to be pessimistic about our ability to influence patient outcomes because we are uncertain about the best course of action. The authors of this article provide excellent information about how we can-and should-help ill and injured patients return to work.

As I read the article, I reflected on my own experience providing patients with advice about returning to work. Two points, in particular, struck a chord with me.

1. Many factors in the process are beyond our control. The physician's role in helping patients return to work after an injury or illness is limited. The authors remind us that there are many patient and employer factors that are beyond our control and that influence patients' successful return to work. Patient factors include motivation, mental health, and job satisfaction. Employer factors include job flexibility and disability benefits and policies. And of course, there are system factors that include laws governing work-related disability.

2. Our role, while limited, is important. By putting forth a positive attitude toward recovery and providing encouragement to patients, we can facilitate an earlier return to work.

I am cognizant of the pivotal role we can play with back injuries, a frequent cause of work disability. A great deal of excellent research over the past 20 years guides us regarding treatment and prognosis. Most back injuries are due to musculoskeletal injury and improve quickly during the first week, no matter what the therapy. By steering these patients clear of narcotics, telling them to remain as physically active as their pain will allow, and letting them know they will recover, we can pave the way for an early return to work.

Let us all take full advantage, then, of these important conversations with our patients. Armed with the strategies in this month's article, we can increase the likelihood of our patients' success.

\section{THE JOURNAL OF

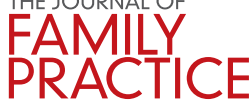

EDITOR-IN-CHIEF

JOHN HICKNER, MD, MSC

Professor Emeritus

Michigan State University

College of Human Medicine

ASSOCIATE EDITOR

RICHARD P. USATINE, MD

University of Texas Health,

San Antonio (Photo Rounds)

ASSISTANT EDITORS

DOUG CAMPOS-OUTCALT, MD, MPA

University of Arizona

RICK GUTHMANN, MD, MPH

Advocate Illinois Masonic Family Medicine

Residency, Chicago

GARY KELSBERG, MD, FAAFP

University of Washington, Renton

COREY LYON, DO

University of Colorado, Denver

KATE ROWLAND, MD, MS

Rush-Copley Medical Center, Chicago

E. CHRIS VINCENT, MD

University of Washington, Seattle

SAMINA YUNUS, MD, MPH

Cleveland Clinic, Chagrin Falls, $\mathrm{OH}$

EDITORIAL BOARD

FREDERICK CHEN, MD, MPH

University of Washington, Seattle

MARK S. JOHNSON, MD, MPH

Howard University College of Medicine

Washington, DC

JEFFREY T. KIRCHNER, DO, FAAFP, AAHIVS

Penn Medicine/Lancaster General Hospital, PA

TRACY MAHVAN, PHARMD

University of Wyoming, Larami

MICHAEL MENDOZA, MD, MPH, MS, FAAFP University of Rochester, NY

FRED MISER, MD, MA

The Ohio State University, Columbus

KEVIN PETERSON, MD, MPH

University of Minnesota, St. Paul

MICHAEL RADDOCK, MD

The MetroHealth System, Cleveland, $\mathrm{OH}$

KATE ROWLAND, MD, MS

Rush-Copley Medical Center, Chicago

LINDA SPEER, MD

University of Toledo, $\mathrm{OH}$

DIRECT INQUIRIES TO:

Frontline Medical Communications

7 Century Drive, Suite 302

Parsippany, NJ 07054

Telephone: (973) 206-3434

Fax: (973) 206-9378

Have a comment or

feedback?

Email: jfp.eic@gmail.com 